\title{
Hormonal diagnosis of 21-hydroxylase deficiency in plasma and urine of neonates using benchtop gas chromatography-mass spectrometry
}

\author{
S A Wudy, M Hartmann and J Homoki \\ Steroid Laboratory, Department of Pediatrics, University of Ulm, Prittwitzstrasse 43, D-89070 Ulm/Donau, Germany \\ (Requests for offprints should be addressed to S A Wudy)
}

\begin{abstract}
We aimed at measuring the first plasma concentrations of 17-hydroxyprogesterone (17OH-P) determined by benchtop isotope dilution/gas chromatography-mass spectrometry (ID/GC-MS) in term neonates with or without 21-hydroxylase deficiency. Plasma samples from normal cord blood specimens $(n=30)$, unaffected neonates $(n=38)$ and neonatal patients with classical 21-hydroxylase deficiency (eight salt-wasters, three simple virilizers) were analyzed. Steroid profiling of random urinary specimens by GC-MS served as a confirmatory test for 21hydroxylase deficiency. 17OH-P (nmol/l) in cord blood plasma lay between 11.66 and 75.92 (median 24.74). It declined shortly after birth. In the first 8 days of life, the time that screening for 21-hydroxylase deficiency is per-
\end{abstract}

formed, 17OH-P ranged between undetected levels and an upper limit of 22.87 (median 4.11). Thereafter (days 9-28) its concentrations lay between $2 \cdot 18$ and $20 \cdot 30$ (median 6.22). Except one simple virilizer, all other patients with 21-hydroxylase deficiency had clearly elevated plasma $17 \mathrm{OH}-\mathrm{P}$ at the time that screening for 21-hydroxylase deficiency would be performed. We suggest ID/GC-MS, which provides the highest specificity in steroid analysis, for checking suspicious concentrations of $17 \mathrm{OH}-\mathrm{P}$ in neonates and underscore the potential of urinary steroid profiling by GC-MS as a rapid, noninvasive and non-selective confirmatory test for congenital adrenal hyperplasia.

Journal of Endocrinology (2000) 165, 679-683

\section{Introduction}

17-Hydroxyprogesterone (17OH-P, 17 $\alpha$-hydroxypregn4-ene-3,20-dione) is the most important plasma parameter for the diagnosis and monitoring of 21-hydroxylase deficiency (New et al. 1989). Currently, neonatal screening procedures for 21-hydroxylase deficiency are based on its determination by immunoassays (Pang \& Clark 1990). However, due to cross-reactivity of antibodies, the complex steroid milieu of the newborn human gives rise to considerable variation in the performance of steroid immunoassays (Honour \& Rumsby 1993).

Analytical methods based on mass spectrometry present the most specific quantitative methods for steroid determination (Middle 1995). In contrast to immunoassays a physicochemical method like isotope dilution/gas chromatography-mass spectrometry (ID/GC-MS) is independent of cross-reactivity. While the technique has primarily been used as a reference method for the evaluation of steroid immunoassays (Middle 1995) or as a research method, we have developed and suggested clinically applicable procedures employing benchtop instrumentation (Wudy et al. 1992, 1993, 1999).
In the work described in this paper we aimed at providing the first mass spectrometric data on the plasma concentrations of $17 \mathrm{OH}-\mathrm{P}$ in neonates unaffected or affected with 21-hydroxylase deficiency. GC-MS furthermore permits the chance of urinary steroid profiling, thus presenting a suitable confirmatory procedure after a positive screening test for 21-hydroxylase deficiency in neonates (Honour \& Brook 1997).

\section{Patients and Methods}

We have studied plasma and random urinary samples collected at the time of diagnosis from 11 term neonates affected with classical 21-hydroxylase deficiency (nine females, two males). Of these, six females and two males had the salt-losing form as shown by typical electrolyte derangements and elevated plasma renin. Apart from one patient (Table 1, patient 7), none had received postnatal treatment. We have furthermore analyzed 30 cord blood plasma samples (mixed cord blood) from term neonates born spontaneously after uneventful pregnancies and plasma specimens from 38 term neonates 
with non-endocrine disorders, of whom none was reported to be critically ill. With the exception of two patients with 21-hydroxylase deficiency (see Tables 1 and 2) none of the neonates investigated had received steroids pre- or postnatally. All urine and plasma specimens were stored at $-20{ }^{\circ} \mathrm{C}$ until the time of assay. Informed consent was obtained from the parents and the study was approved by the local ethical committee.

Plasma 17OH-P was determined according to our own ID/GC-MS procedure (Wudy et al. 1992). In brief, plasma $(0 \cdot 1-0.5 \mathrm{ml})$ was equilibrated with $3.03 \mathrm{pmol}$ of a deuterium-labeled analog of the analyte, 17hydroxy $\left[11,11,12,12-{ }^{2} \mathrm{H}_{4}\right]$ progesterone, which served as an internal standard. After solvent extraction (ethyl acetate) the dried organic extract was purified on $0.5 \mathrm{~g}$ Sephadex LH-20 mini-columns; Pharmacia, Uppsala, Sweden. Then, heptafluorobutyric acid derivatives were prepared and an aliquot $(1 / 12)$ of the processed plasma extract analyzed by GC/MS. Gas chromatography was carried out on an OV-1 fused silica column (MachereyNagel, Düren, Germany; $25 \mathrm{~m} \times 0.20 \mathrm{~mm}$; film thickness $0 \cdot 1 \mu \mathrm{m}$ ) housed in a DANI $6500 \mathrm{GC}$ (Maine-Kastel, Germany) which was directly interfaced to a Hewlett Packard 5970B (Böhlinger, Germany) mass selective detector operated in the selected ion monitoring mode. Quantification was performed using the peak area ratios between the ion pair of the analyte $(\mathrm{m} / \mathrm{z} 465)$ and its corresponding internal standard $(\mathrm{m} / \mathrm{z} 469)$. Intra- and interassay coefficients of variation were 3.5 and $3.8 \%$ respectively. The standard plot was linear: $y=1 \cdot 88 x+0 \cdot 18$; $r=0.999$. Concerning sensitivity, $30.26 \mathrm{pmol}$ of $17 \mathrm{OH}-\mathrm{P}$ gave a signal-to-noise ratio of $5 \cdot 3$. Accuracy was determined by spiking plasma with known amounts of steroids. The agreement between the values found and the amounts added was excellent with a relative error less than $7 \cdot 5 \%$.

The method used for profiling steroids in urine of newborn infants followed the previously reported routine procedure (Shackleton \& Honour 1976, Honour 1986). It consisted of solid phase extraction, separation of free and glucuronidated steroids by LH-20 chromatography, enzymatic hydrolysis, extraction, derivative formation (methyloxime-trimethylsityl-ethers) and GC-MS analysis. Diagnosis of 21-hydroxylase deficiency was based on mass spectrometric identification of four indicative steroids: pregnanetriol (PT, $5 \beta$-pregnane-3 $\alpha, 17 \alpha, 20 \alpha-$ triol), pregnanetriolone (11O-PT, 11-oxo-pregnanetriol, $3 \alpha, 17 \alpha, 20 \alpha$-trihydroxy- $5 \beta$-pregnan-11-one), 17-hydroxypregnanolone (17OH-PO, $3 \alpha, 17 \alpha$-dihydroxy- $5 \beta$-pregnan20 -one) and 15 $\beta$-hydroxy-pregnanolone (15OH-PO, $3 \alpha, 15 \beta, 17 \alpha$-trihydroxy- $5 \beta$-pregnan-20-one).

\section{Results}

Application of our ID/GC-MS assay for plasma 17OH-P in a clinical setting is demonstrated by the example of
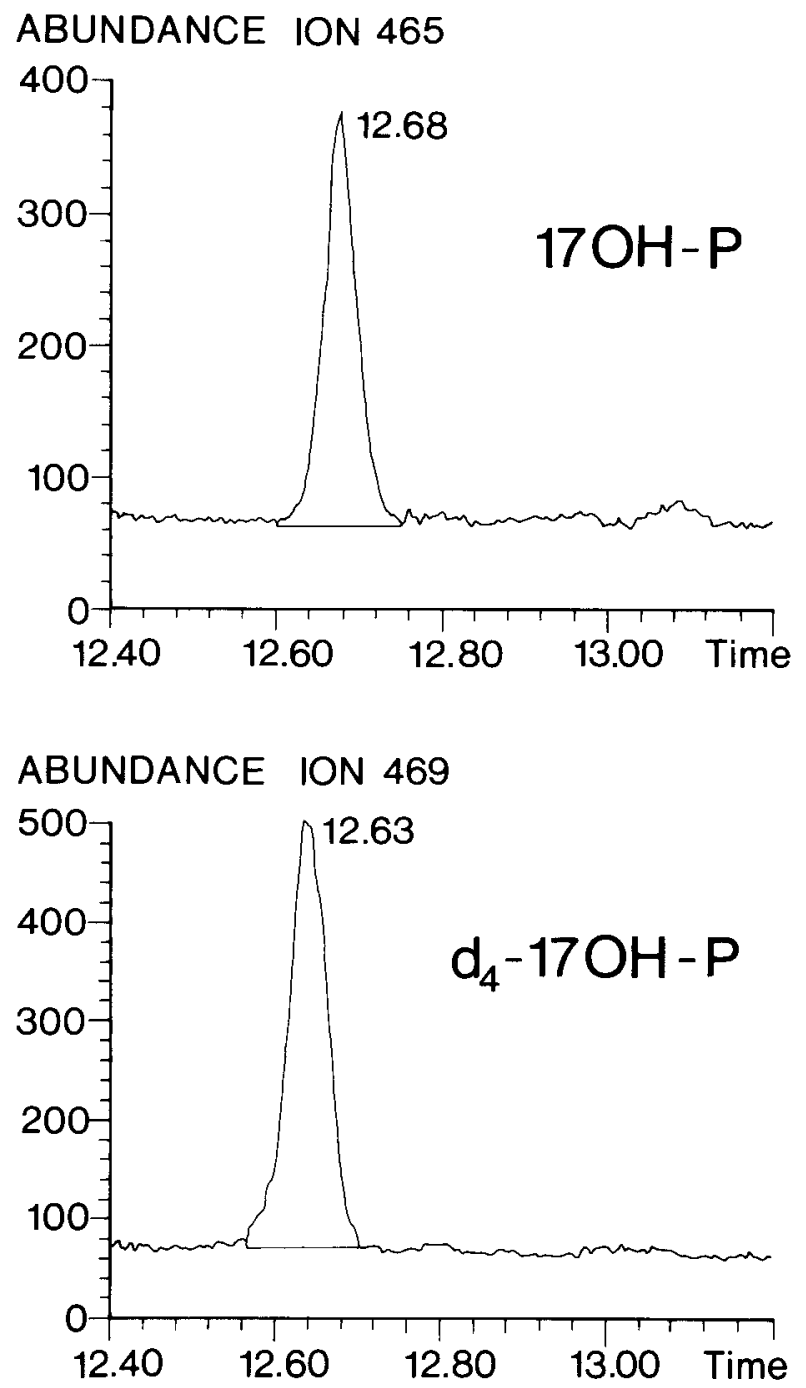

Figure 1 Portions of a selected ion recording chromatogram of an aliquot $(1 / 12)$ of a processed extract of $0 \cdot 1 \mathrm{ml}$ of plasma of a healthy neonate. The ion traces of the analyte $(17 \mathrm{OH}-\mathrm{P}, \mathrm{m} / \mathrm{z} 465$, above $)$ and its corresponding internal standard $\left(\left[{ }^{2} \mathrm{H}_{4}\right] 17 \mathrm{OH}-\mathrm{P}, \mathrm{m} / \mathrm{z}\right.$ 469 , below) have been superposed.

typical ion chromatograms. Figure 1 shows the determination of $17 \mathrm{OH}-\mathrm{P}$ in $0.1 \mathrm{ml}$ plasma of a normal neonate.

The concentrations of $17 \mathrm{OH}-\mathrm{P}$ in cord blood plasma and plasma of neonates not affected with 21-hydroxylase deficiency are depicted in Fig. 2. We could not find any sex differences and have therefore pooled data of female and male neonates. $17 \mathrm{OH}-\mathrm{P}$ rapidly declined after birth. Since screening for 21-hydroxylase deficiency is carried out in the first days of life (Pang \& Clark 1990), we have grouped the data into 2-day intervals for the first 8 postnatal days to allow for better comparison. The concentrations of $17 \mathrm{OH}-\mathrm{P}$ in unaffected individuals did not 


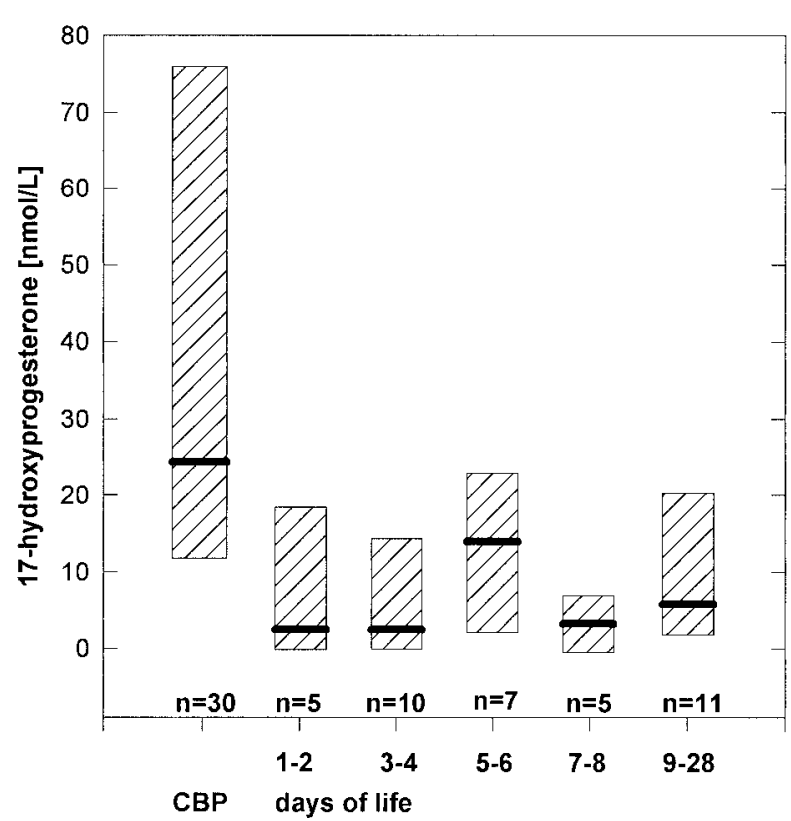

Figure 2 Concentrations of $17 \mathrm{OH}-\mathrm{P}(\mathrm{nmol} / \mathrm{l})$ determined by ID/GC-MS in cord blood plasma (CBP) and postnatal plasma specimens of neonates not affected with 21-hydroxylase deficiency. Ranges are presented by boxes and bars indicate the medians. Conversion: $\mathrm{nmol} / \mathrm{l} \times 0.33 \mathrm{ng} / \mathrm{ml}$.

show much fluctuation and did not exceed an upper range limit of $22.87 \mathrm{nmol} / 1$ during the whole neonatal period.

Clinical and hormonal data of patients with 21hydroxylase deficiency are summarized in Table 1 (saltwasters) and Table 2 (simple virilizers). One simple virilizer had normal $17 \mathrm{OH}-\mathrm{P}$ on the 4 th day of life. All other patients - including a salt-waster in whom hydrocortisone therapy had already been administered for 1 day - had elevated 17OH-P. Urinary steroid analysis confirmed the diagnoses of 21-hydroxylase deficiency by identifying all four indicative steroid metabolites in corresponding random urine specimens.

\section{Discussion}

Widely divergent plasma levels for $17 \mathrm{OH}-\mathrm{P}$ in cord blood plasma and plasma of neonates have been published so far; especially, direct immunoassays overestimate $17 \mathrm{OH}-\mathrm{P}$ concentrations (Forest \& Cathiard 1978, Hughes et al. 1979). This is impressively reflected by the considerable variability among cut-off levels of different screening programs (Pang \& Clark 1990). It has been demonstrated that the interference of steroid sulfates from the fetal adrenal zone, mainly $17 \mathrm{OH}-\mathrm{PO}$ sulfate, can lead to false-positive elevated 17OH-P levels (Wong et al. 1992). The production of steroid sulfates in the fetal adrenal zone lasts well into infancy (Shackleton 1984). However, neither solvent extraction nor chromatographic steps necessarily improve the diagnostic efficiency of an immunoassay (Wudy et al. 1994).

These findings are important for screening programs for 21-hydroxylase deficiency, where, for reasons of practicability, direct immunologic procedures are advantageous but are likely to produce false-positive elevated results. In this study, our most important goal was to provide the first data on $17 \mathrm{OH}-\mathrm{P}$ in neonates unaffected or affected with 21-hydroxylase deficiency using isotope dilution mass spectrometry, currently the most specific method in steroid analysis. Our data in unaffected neonates permit orientation when comparing reference ranges established by immunoassays.

All our patients with the salt-wasting form of 21hydroxylase deficiency had clearly elevated $17 \mathrm{OH}-\mathrm{P}$ at the time of diagnosis. In the patient in whom a plasma sample was drawn on day 1 , elevated plasma $17 \mathrm{OH}-\mathrm{P}$ already permitted diagnosis on the 1st day of life (Table 1, patient 1). $17 \mathrm{OH}-\mathrm{P}$ was still elevated in another patient

Table 1 Hormonal diagnosis of 21-hydroxylase deficiency by mass spectrometry in plasma and urine: salt-wasters

\begin{tabular}{|c|c|c|c|c|c|c|c|c|c|}
\hline \multirow[b]{3}{*}{ Patient } & \multirow[b]{2}{*}{ Sex } & \multirow[b]{2}{*}{ Prader stage } & \multicolumn{2}{|c|}{ Plasma specimens } & \multicolumn{5}{|l|}{ Urinary specimens } \\
\hline & & & Day of life & $17 \mathrm{OH}-\mathrm{P}(\mathrm{nmol} / \mathrm{l})$ & Day of life & $17 \mathrm{OH}-\mathrm{PO}$ & $15 \mathrm{OH}-\mathrm{PO}$ & PT & 11O-PT \\
\hline & & & & & & & & & \\
\hline 1 & & & 5 & $437 \cdot 4$ & 5 & + & + & + & + \\
\hline 2 & $46, X X$ & 3 & 3 & $66 \cdot 2$ & 3 & + & + & + & + \\
\hline 3 & $46, X X$ & 4 & 5 & $498 \cdot 9$ & 3 & + & + & + & + \\
\hline 6 & $46, X X$ & 3 & 7 & $215 \cdot 4$ & 5 & + & + & + & + \\
\hline $7 * *$ & $46, X Y$ & Normal male & 19 & $41 \cdot 9$ & 19 & + & + & + & + \\
\hline 8 & $46, X X$ & 4 & 24 & $659 \cdot 1$ & 24 & + & + & + & + \\
\hline
\end{tabular}

\footnotetext{
*After prenatal diagnosis and intrauterine dexamethasone treatment.

**Plasma and urine were obtained 1 day after therapy with hydrocortisone had been started.

+Indicates steroid was identified by GC-MS.
} 
Table 2 Hormonal diagnosis of 21-hydroxylase deficiency by mass spectrometry in plasma and urine: simple virilizers

\begin{tabular}{|c|c|c|c|c|c|c|c|c|c|}
\hline & \multirow[b]{2}{*}{ Sex } & \multirow[b]{2}{*}{ Prader stage } & \multicolumn{2}{|c|}{ Plasma specimens } & \multicolumn{5}{|l|}{ Urinary specimens } \\
\hline & & & Day of life & $17 \mathrm{OH}-\mathrm{P}(\mathrm{nmol} / \mathrm{l})$ & Day of life & $17 \mathrm{OH}-\mathrm{PO}$ & $15 \mathrm{OH}-\mathrm{PO}$ & PT & 11O-PT \\
\hline \multicolumn{10}{|c|}{ Patient } \\
\hline \multirow[t]{2}{*}{2} & $46, X X$ & 2 & 4 & $17 \cdot 4$ & No sample available & - & - & - & - \\
\hline & & & 6 & $122 \cdot 4$ & 6 & + & + & + & + \\
\hline 3 & $46, X X$ & 2 & 13 & $246 \cdot 0$ & 13 & + & + & + & + \\
\hline
\end{tabular}

+Indicates steroid was identified by GC-MS.

who had received hydrocortisone for 1 day because he presented with a life-threatening salt-loss crisis (Table 1, patient 7). Interestingly this patient was missed by prenatal molecular biology testing. Unfortunately, no immediate postnatal confirmation of diagnosis was done and screening for 21-hydroxylase deficiency was not carried out in the area in which the hospital was located.

Patients with the simple virilizing form of 21hydroxylase deficiency generally had lower $17 \mathrm{OH}-\mathrm{P}$ at the time of diagnosis and affected females had less degree of genital virilization. However, in one case of simple virilizing 21-hydroxylase deficiency, a first specimen on the 4th day of life was normal (Table 2). A second sample obtained 2 days later demonstrated an elevated $17 \mathrm{OH}-\mathrm{P}$ in a virilized female simple virilizer (patient 2 , Table 2). This shows that even if screening were performed by the most specific technique, cases of simple virilizers might be missed.

In contrast to procedures merely based on gas chromatography, mass spectrometry permits reliable detection of 21-hydroxylase deficiency by urinary steroid profiling from the first days of life onwards (Honour 1986, Yong et al. 1988). The present study, in which random urine samples have been used, confirms these findings. $17 \mathrm{OH}-\mathrm{P}$, the marker hormone of 21-hydroxylase deficiency, is catabolized to PT and further to different 17-hydroxypregnanolones like 17OH-PO. Another plasma marker of 21-hydroxylase deficiency, 21deoxycortisol, is metabolized into $11 \mathrm{O}-\mathrm{PT}$. In neonates, steroids like $15 \mathrm{OH}-\mathrm{PO}$ have been described as unique markers of 21-hydroxylase deficiency (Joannou 1981). Urinary steroid profiling by GC-MS permits the advantage of being non-selective. The technique not only permits detection of all the other virilizing adrenal enzyme defects, 3 $\beta$-hydroxysteroid dehydrogenase deficiency and $11 \beta$-hydroxylase deficiency but also delineates further causes of salt-losing states like lipoid adrenal hyperplasia, defects of aldosterone biosynthesis (18-hydroxylase defect, 18-oxidation defect) and congenital adrenal hypoplasia (Honour \& Brook 1997, Wudy et al. 1997). After a positive screening test for 21-hydroxylase deficiency, the diagnosis needs to be validated with a confirmatory test. Urinary steroid profiling of random urine specimens by
GC-MS seems to be best suited as a confirmatory procedure, because it presents a non-invasive and nonselective procedure with highest specificity. It is rapid, results are available within 3 working days after receipt of sample.

In this study plasma and urinary steroid analyses were done using cost-effective and reliable benchtop GC-MS equipment, demonstrating that mass spectrometric steroid analysis can be performed clinically in a routine setting. Concerning sample throughput, GC-MS of course cannot compete with direct immunoassays and therefore is not suited as a screening procedure. However, individual laboratories with appropriate GC-MS equipment should be able to develop rapid and cost-effective ways of measuring plasma and urinary steroids on a routine basis (Honour 1986, Shackleton et al. 1990, Wudy et al. 1997, 1999).

To conclude, we have presented the first mass spectrometric data on the concentrations of $17 \mathrm{OH}-\mathrm{P}$ in neonates unaffected or affected with 21-hydroxylase deficiency. We speculate that screening for 21-hydroxylase deficiency will detect all cases of salt-wasters but may miss some cases of simple virilizers. GC-MS profiling of urinary steroids provides the opportunity of a non-invasive, rapid, highly specific and non-selective confirmatory test for congenital adrenal hyperplasia.

\section{Acknowledgements}

The authors thank Mrs H Pinzer and Mrs E Ambach for excellent technical assistance. S A W acknowledges support by a grant from the Deutsche Forschungsgemeinschaft (DFG WU 148/3).

\section{References}

Forest MG \& Cathiard AM 1978 Ontogenetic study of plasma $17 \alpha$-hydroxyprogesterone in the human. I. Postnatal period: evidence for a transient ovarian activity in infancy. Pediatric Research 12 6-11.

Honour JW 1986 Biochemical aspects of congenital adrenal hyperplasia. Journal of Inherited Metabolic Disease 9 (Suppl 1) 124-134. 
Honour JW \& Brook CGD 1997 Clinical indications for the use of urinary steroid profiles in neonates and children. Annals of Clinical Biochemistry 34 45-54.

Honour JW \& Rumsby G 1993 Problems in diagnosis and management of congenital adrenal hyperplasia due to 21hydroxylase deficiency. Journal of Steroid Biochemistry and Molecular Biology 45 69-74.

Hughes IA, Riad-Fahmy D \& Griffiths K 1979 Plasma 17-hydroxyprogesterone concentrations in newborn infants. Archives of Disease in Childhood 54 347-349.

Joannou GE 1981 Identification of $15 \beta$-hydroxylated C21 steroids in the neonatal period. The role of $3 \alpha, 15 \beta, 17 \alpha$-trihydroxy- $5 \beta$ pregnan-20-one in the perinatal diagnosis of congenital adrenal hyperplasia $(\mathrm{CAH})$ due to a 21-hydroxylase deficiency. Journal of Steroid Biochemistry 14 901-912.

Middle JG 1995 The quality assessment of steroid hormone assays. In Steroid Analysis, edn 1, pp 647-696. Eds HLJ Makin, DB Gower \& DN Kirk. London: Blackie Academic \& Professional.

New MI, White PC, Pang S, Dupont B \& Speiser PW 1989 The adrenal hyperplasias. In The Metabolic Basis of Inherited Disease, edn 6, pp 1881-1917. Eds CR Scriver, AL Beaudet, WS Sly \& D Valle. New York: McGraw-Hill.

Pang S \& Clark A 1990 Newborn screening, prenatal diagnosis, and prenatal treatment of congenital adrenal hyperplasia due to 21hydroxylase deficiency. Trends in Endocrinology and Metabolism 1 300-307.

Shackleton CHL 1984 Steroid synthesis and catabolism in the fetus and neonate. In Biochemistry of Steroid Hormones, edn 2, pp 441-477. Ed. HLF Makin. London: Blackwell Scientific Publications.

Shackleton CHL \& Honour JW 1976 Simultaneous estimation of urinary steroids by semiautomated gas chromatography. Investigation of neonatal infants and children with abnormal steroid synthesis. Clinica et Chimica Acta 69 267-283.

Shackleton CHL, Merdinck J \& Lawson AM 1990 Steroid and bile acid analyses. In Mass Spectrometry of Biological Materials, edn 1, pp 297-377. Eds CN McEwen \& B Larsen. New York: Marcel Dekker.
Wong T, Shackleton CHL, Covey TR \& Ellis G 1992 Identification of steroids in neonatal plasma that interfere with $17 \alpha-$ hydroxyprogesterone radioimmunoassays. Clinical Chemistry $\mathbf{3 8}$ 1830-1837.

Wudy SA, Wachter UA, Homoki J, Teller WM \& Shackleton CHL 1992 Androgen metabolism assessment by routine gas chromatography/mass spectrometry profiling of plasma steroids: part 1 , unconjugated steroids. Steroids 57 319-324.

Wudy SA, Wachter UA, Homoki J \& Teller WM 1993 Determination of dehydroepiandrosterone sulfate in human plasma by gas chromatography/mass spectrometry using a deuterated internal standard: a method suitable for routine clinical use. Hormone Research 39 235-240.

Wudy SA, Wachter UA, Benz R, Homoki J, Shackleton CHL \& Teller WM 1994 Determination of unconjugated and conjugated key steroids of androgen metabolism in human plasma by routine GC/MS using stable isotope labeled internal standards. In Advances in Steroid Analysis '93, edn 1, pp 263-271. Ed. S Görög. Budapest: Akademiai Kiado.

Wudy SA, Wachter UA, Homoki J \& Teller WM 1997 Diagnosis of congenital adrenal hyperplasia due to $11 \beta$-hydroxylase deficiency by gas chromatography and mass spectrometric analysis of urinary steroids. Deutsche Medizinische Wochenschrift 122 3-10.

Wudy SA, Dörr HG, Solleder C, Djalali M \& Homoki J 1999 Profiling steroid hormones in amniotic fluid of midpregnancy by routine stable isotope dilution/gas chromatography-mass spectrometry: reference values and concentrations in fetuses at risk for 21-hydroxylase deficiency. Journal of Clinical Endocrinology and Metabolism 84 2724-2728.

Yong ABW, Pitt JJ, Montalto J, Davies HE, Warne GL \& Connelly JF 1988 Diagnosis of 21-hydroxylase deficiency in newborn infants by GC-MS of urinary steroids. Australian Paediatric Journal $\mathbf{2 4}$ 280-285.

Received 5 October 1999

Revised manuscript received 24 December 1999 Accepted 27 January 2000 